\title{
Abnormalities in plasmas concentrations of lipoproteins and fibrinogen in Type 1 (insulin-dependent) diabetic patients with increased urinary albumin excretion
}

\author{
T.Jensen ${ }^{1}$, S. Stender ${ }^{2}$ and T. Deckert ${ }^{1}$ \\ ${ }^{\uparrow}$ Steno Memorial Hospital, Gentofte and ${ }^{2}$ KAS Gentofte, Department of Clinical Chemistry, Hellerup, Denmark
}

\begin{abstract}
Summary. Type 1 (insulin-dependent) diabetic patients with clinical nephropathy have a more than ten-fold increase in mortality of cardiovascular diseases compared with diabetic patients without nephropathy. The risk factors for cardiovascular disease, plasma concentrations of lipoproteins and fibrinogen, were investigated in 74 long-term diabetic patients: 37 with normal urinary albumin excretion, 20 with incipient nephropathy and 17 with overt clinical nephropathy based on urinary albumin excretion. The groups were matched according to sex, age and diabetes duration. The concentration of plasma cholesterol, very low density lipoprotein cholesterol, low density lipoprotein cholesterol, triglyceride and fibrinogen rose with increasing urinary albumin excretion. The plasma concentrations of these lipoproteins and fibrinogen were $11-14 \%$ higher in the patients with incipient nephropathy and $26-87 \%$ higher in the patients with overt clinical ne-
\end{abstract}

phropathy compared with the patients without nephropathy. The plasma concentration of high density lipoprotein cholesterol was unaffected by albuminuria. Patients with normal urinary albumin excretion and $\mathrm{HbA}_{1 \mathrm{c}}>8.0 \%$ had significantly higher very low density lipoprotein- and lower high density lipoprotein cholesterol concentrations compared with patients with $\mathrm{HbA}_{1 \mathrm{c}}<8.0 \%$. Simple addition of the described risk factors can only account for a minor part of the greatly increased cardiovascular mortality in patients with diabetic nephropathy. An additional and possibly more decisive factor might be a change in the arterial wall, a change which promotes lipid accumulation and/or facilitates thrombus formation.

Key words: Type 1 (insulin-dependent) diabetes, urinary al-

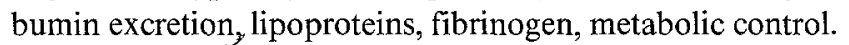

Recent epidemiological studies have shown that Type 1 (insulin-dependent) and Type 2 (non-insulindependent) diabetic patients developing diabetic nephropathy have an up to 30 -fold increase in mortality compared with diabetic patients not developing nephropathy [1-3]. A substantial part of this excess mortality is caused by cardiovascular diseases [4]. In a previous study of Type 1 diabetic patients the cumulative incidence of coronary heart disease within 6 years after onset of proteinuria was $40 \%$ versus $5 \%$ in patients without proteinuria [5].

Higher smoking frequency [6], elevated blood pressure $[7,8]$, increased plasma fibrinogen concentration and increased thrombocyte aggregation [9] are frequently present in diabetic patients with proteinuria. Furthermore, atherogenic plasma lipid and lipoprotein abnormalities are described in these patients [10-12]. However, it is not known to what extent these changes are seen at the early stage of diabetic nephropathy.

Therefore, in the present study plasma concentration of lipoproteins and fibrinogen were investigated in long-term Type 1 diabetic patients with different levels of urinary albumin excretion (UalbV) (normal range to overt diabetic nephropathy).

\section{Subjects and methods}

\section{Patients}

Seventy-four non-obese patients with Type 1 diabetes (onset before age 31) were recruited from the outpatient clinic at the Steno Memorial Hospital. All patients had a diabetes duration of more than 5 years. Their current age was between 18 and 50 years. They had no history of non-diabetic renal disease and all had a negative bacterial culture of the urine. All subjects gave their informed consent to participate in the study. All received conventional insulin treatment, i. e. 2-3 daily injections of intermediate-acting insulin often mixed with short-acting insulin. The composition of food intake was carefully calculated for each patient; $50-55 \%$ of the total calories consisted of carbohydrates, $30-35 \%$ of fat and $15 \%$ of proteins. None of the patients had ketoacidosis or a history of habitual alcohol intake.

The patients were recruited from 3 groups according to level of albuminuria.

Group 1: patients with normal UalbV $(<30 \mathrm{mg} / 24 \mathrm{~h})(n=37)$.

Group 2: patients with elevated UalbV in the range of $30-300 \mathrm{mg}$ / 24 h, i.e. patients with incipient diabetic nephropathy $(n=20)$.

Group 3: patients with diabetic nephropathy (UalbV $>300 \mathrm{mg} / 24 \mathrm{~h}$ ) $(n=17)$.

The level of albuminuria was determined on the basis of the median UalbV in three 24-h urine collections performed at home during normal physical activity. This was done in order to take into account the high (50\%) day-to-day variation of the 24-h UalbV [13]. 
Table 1. Clinical data of the patients

\begin{tabular}{|c|c|c|c|c|c|c|c|}
\hline \multirow[b]{3}{*}{ Number $(M / F)$} & \multicolumn{3}{|c|}{$\begin{array}{l}\text { Normal urinary albumin excretion } \\
\text { (UalbV }<30 \mathrm{mg} / 24 \mathrm{~h} \text { ) }\end{array}$} & \multirow{2}{*}{\multicolumn{2}{|c|}{$\begin{array}{l}\text { Incipient nephropathy } \\
\text { (UalbV } 30-300 \mathrm{mg} / 24 \mathrm{~h}) \\
\text { Group } 2\end{array}$}} & \multicolumn{2}{|c|}{$\begin{array}{l}\text { Clinical nephropathy } \\
\text { (UalbV }>300 \mathrm{mg} / 24 \mathrm{~h} \text { ) }\end{array}$} \\
\hline & $\begin{array}{l}\mathrm{HbA}_{1 \mathrm{c}}<8.0 \% \\
\text { Group } 1 \mathrm{a}\end{array}$ & \multicolumn{2}{|c|}{$\begin{array}{l}\mathrm{HbA}_{1 \mathrm{c}} \geq 8.0 \% \\
\text { Group } 1 \mathrm{~b}\end{array}$} & & & \multicolumn{2}{|c|}{ Group 3} \\
\hline & $(8 / 11)$ & 18 & $(7 / 11)$ & 20 & $(9 / 11)$ & 17 & $(7 / 10)$ \\
\hline $\mathrm{UalbV}(\mathrm{mg} / 24 \mathrm{~h})^{\mathrm{e}}$ & $8 \quad(4-21)^{c, d}$ & 11 & $(2-26)^{c, d}$ & 97 & $(39-299)^{\mathrm{a}, \mathrm{b}, \mathrm{d}}$ & 645 & $(305-3391)^{a, b, c}$ \\
\hline $\mathrm{HbA}_{1 \mathrm{c}}(\%)$ & $6.9( \pm 0.5)^{b, c, d}$ & 9.0 & $( \pm 0.6)^{\mathrm{a}}$ & 8.9 & $( \pm 1.9)^{\mathrm{a}}$ & 9.4 & $( \pm 1.5)^{\mathrm{a}}$ \\
\hline Blood glucose $(\mathrm{mmol} / \mathrm{l})$ & $9.8( \pm 4.7)$ & 12.0 & $( \pm 5.6)$ & 9.7 & $( \pm 4.9)$ & 11.8 & $( \pm 5.3)$ \\
\hline Blood pressure $(\mathrm{mm} \mathrm{Hg})$ & $87 \quad( \pm 8)^{\mathrm{c}, \mathrm{d}}$ & 87 & $( \pm 9)^{c, d}$ & 97 & $( \pm 13)^{a, b}$ & 103 & $( \pm 10)^{a, b}$ \\
\hline Free p-insulin (pmol/e) & $49 \quad( \pm 25)$ & 50 & $( \pm 24)$ & 57 & $( \pm 24)$ & 54 & $( \pm 22)$ \\
\hline Insulin dose (IU/ $/ \mathrm{kg} / 24 \mathrm{~h})$ & $0.62( \pm 0.17)$ & 0.65 & $( \pm 0.15)$ & 0.61 & $( \pm 0.18)$ & 0.72 & $2( \pm 0.24)$ \\
\hline S-Creatinine $(\mu \mathrm{mol} / 1)$ & $81 \quad( \pm 14)^{\mathrm{d}}$ & 76 & $( \pm 10)^{d}$ & 82 & $( \pm 15)^{\mathrm{d}}$ & 95 & $( \pm 26)^{a, b, c}$ \\
\hline S-albumin $(\mu \mathrm{mol} / \mathrm{l})$ & $( \pm 36)^{d}$ & 551 & $( \pm 37)^{d}$ & 554 & $( \pm 45)^{\mathrm{d}}$ & 497 & $( \pm 58)^{\mathrm{a}, \mathrm{b}, \mathrm{c}}$ \\
\hline
\end{tabular}

${ }^{\mathrm{a}}$ denotes $p<0.05$ from Group $1 \mathrm{a} ;{ }^{\mathrm{b}}$ denotes $p<0.05$ from Group $1 \mathrm{~b} ;{ }^{\mathrm{c}}$ denotes $p<0.05$ from Group 2; ${ }^{\mathrm{d}}$ denotes $p<0.05$ from Group 3 Results are given as mean $\pm \mathrm{SD}$ except ${ }^{\mathrm{e}}$ median and range

To evaluate the influence of long-term metabolic control Group I was further subdivided into: Group $1 \mathrm{a}$ : good metabolic control $\left(\mathrm{HbA}_{1 \mathrm{c}}<8.0 \%\right) ; n=19$ and Group 1b: poor metabolic control $\left.\left(\mathrm{HbA}_{1 \mathrm{c}} \geq 8.0 \%\right) ; n=18\right)$. The 4 groups were matched as to sex, age and diabetes duration. The frequency of estrogen users among the women was the same in the four groups (Table 1). Beyond this, no subject was taking drugs other than insulin known to affect the levels of lipoproteins and fibrinogen or had any disease other than diabetes known to affect lipoprotein metabolism.

\section{Laboratory measurements}

All patients were studied after an 8-h fast and before insulin injection in the morning. A cannula was inserted in the antecubital vein and blood collection was made after $30 \mathrm{~min}$ of lying at rest. Plasma was separated immediately.

Lipids and lipoproteins. Plasma was stored at $4^{\circ} \mathrm{C}$ and within $24 \mathrm{~h}$ an aliquot $(1.5 \mathrm{ml})$ was adjusted to a density of 1.019 by addition of a solution of sodium chloride and sodium bromide [14]. Another $1.5 \mathrm{ml}$ aliquot from the same sample was adjusted to a density of 1.063. The samples were ultracentrifuged at $1.58 \times 10^{6} \times g \times \min (40.3$ Beckman rotor at $4^{\circ} \mathrm{C}$ ), after which the top and bottom fractions were separated by tube slicing. Cholesterol and triglyceride in total plasma and cholesterol in the various ultracentrifuged fractions were determined enzymatically (Boehringer, Mannheim, FRG, CHODPAP method and GPO-PAP method respectively). The top fraction of the first tube $(\mathrm{d}<1.019)$ contained very low density lipoprotein (VLDL). The bottom fraction of the second tube ( $d>1.063)$ contained high density lipoprotein (HDL). The mean recovery of cholesterol after tube slicing was $97.5 \% \pm 3.5 \%$. Low density lipoprotein (LDL) cholesterol $(1.019<\mathrm{d}<1.063)$ was calculated by subtracting HDL cholesterol and VLDL cholesterol from total cholesterol.

Fibrinogen in plasma was determined as trombine coagulable fibrinogen as described by Jacobsen [15]. $\mathrm{HbA}_{1 \mathrm{c}}$ was measured by a chromatographic technique [16]. The normal range was $4.1-6.4 \%$. Serum albumin ( $\mu \mathrm{mol} / \mathrm{l})$ and urinary albumin excretion $(\mathrm{mg} / 24 \mathrm{~h})$ were measured using an ELISA assay [13]. Serum creatinine ( $\mu \mathrm{mol} /$ 1) was measured by a reaction rate kinetic principle eliminating pseudocreatinines [17]. Blood-glucose was measured using Hypocount (Suffolk, England). Free insulin in plasma was determined after immediate centrifugation and polyethylene glycol precipitation as described by Hanning [18].
Insulin dose was given in $\mathrm{IU} / \mathrm{kg}$ body weight. Blood pressure was measured with a standard clinical sphygmomanometer (cuff $25 \times 12 \mathrm{~cm}$ ). Diastolic blood pressure was measured at disappearance of the Korotkoff sounds (phase 5). Results are given as mean blood pressure. The eye background was examined by ophthalmoscopy through the dilated pupil and classified as normal, simplex or proliferative retinopathy. Smokers were all subjects smoking one or more cigarettes per day. All others are non-smokers. Body mass in$\operatorname{dex}(\mathrm{BMI})$ was calculated as weight $/ \mathrm{height}^{2}\left(\mathrm{~kg} / \mathrm{m}^{2}\right)$. Recommended daily energy intake is given in $\mathrm{kJ}$.

\section{Statistical analysis}

Results are given as mean \pm SD and median and range when values were normal, or not normally distributed respectively. Unpaired Student's t-tests were used for comparison between groups when values were normally distributed; otherwise the Mann-Whitney test was used. Correlations were sought using stepwise multiple linear regression analysis. In this analysis log transformed values of UalbV, triglyceride and fibrinogen were used.

\section{Results}

The patients' clinical data are shown in Table 1. The nearly perfect match of the four groups as to blood glucose, free insulin in plasma, insulin dose, BMI, smoking frequency and total daily energy intake is demonstrated. The group with clinical nephropathy had a higher mean blood pressure and serum creatinine level and a lower serum albumin level than the groups with normal UalbV. The 18 patients with normal UalbV and $\mathrm{HbA}_{1 \mathrm{c}}>8.0 \%$ (Group $1 \mathrm{~b}$ ) matched as to long-term metabolic control closely with the patients in Groups 2 and 3.

The plasma concentration of cholesterol, VLDLcholesterol, LDL-cholesterol, triglyceride and fibrinogen were significantly higher in the patients with 
Table 2. Plasma concentration of lipids and fibrinogen

\begin{tabular}{|c|c|c|c|c|}
\hline & \multicolumn{2}{|c|}{$\begin{array}{l}\text { Normal urinary albumin excretion } \\
\text { (UalbV }<30 \mathrm{mg} / 24 \mathrm{~h} \text { ) }\end{array}$} & \multirow{2}{*}{$\begin{array}{l}\begin{array}{l}\text { Incipient nephropathy } \\
\text { (UalbV } 30-300 \mathrm{mg} / 24 \mathrm{~h})\end{array} \\
\text { Group } 2\end{array}$} & \multirow{2}{*}{$\begin{array}{l}\begin{array}{l}\text { Clinical nephropathy } \\
(\text { UalbV }>300 \mathrm{mg} / 24 \mathrm{~h})\end{array} \\
\text { Group } 3\end{array}$} \\
\hline & $\begin{array}{l}\mathrm{HbA}_{1 \mathrm{c}}<8.0 \% \\
\text { Group } 1 \mathrm{a}\end{array}$ & $\begin{array}{l}\mathrm{HbA}_{1 \mathrm{c}} \geq 8.0 \% \\
\text { Group } 1 \mathrm{~b}\end{array}$ & & \\
\hline & $4.97( \pm 0.71)^{d}$ & $4.68( \pm 0.81)^{\mathrm{d}}$ & $5.23( \pm 1.03)$ & $6.08( \pm 1.20)^{\mathrm{a}, \mathrm{b}}$ \\
\hline $\begin{array}{l}\text { VLDL-cholesterol } \\
\qquad(\mathrm{mmol} / \mathrm{l})^{1}\end{array}$ & $0.35( \pm 0.05)^{b, c, d}$ & $0.57( \pm 0.08)^{\mathrm{a}, \mathrm{d}}$ & $0.63( \pm 0.09)^{\mathrm{a}}$ & $1.07( \pm 0.23)^{\mathrm{a}, \mathrm{b}}$ \\
\hline Triglyceride $(\mathrm{mmol} / \mathrm{l})^{2}$ & $0.72(0.43-1.40)^{\mathrm{d}}$ & $0.98 \quad(0.51-2.19)^{\mathrm{d}}$ & $0.95(0.38-2.66)^{d}$ & $1.28(0.57-5.32)^{\mathrm{a}, \mathrm{b}, \mathrm{c}}$ \\
\hline Fibrinogen $(\text { umol/l })^{2}$ & $7.70 \quad(5.80-9.96)^{d}$ & $7.62(5.16-11.52)^{d}$ & $8.68 \quad(5.24-12.85)$ & $9.62(6.04-13.73)^{\mathrm{a}, \mathrm{b}}$ \\
\hline
\end{tabular}

${ }^{\mathrm{a}}$ denotes $p<0.05$ from Group $1 \mathrm{a} ;{ }^{\mathrm{b}}$ denotes $p<0.05$ from Group $1 \mathrm{~b} ;{ }^{\mathrm{c}}$ denotes $p<0.05$ from Group 2; ${ }^{\mathrm{d}}$ denotes $p<0.05$ from Group 3 Results are given as ${ }^{1}$ mean $\pm \mathrm{SD}$ and ${ }^{2}$ median and range

Table 3. Correlation coefficients with UalbV and $\mathrm{HbA} A_{1 c}$ as independent variables

\begin{tabular}{lcc}
\hline & LOG UalbV & $\mathrm{HbA}_{1 \mathrm{c}}$ \\
\hline VLDL-cholesterol & $0.49^{\mathrm{a}}$ & $0.39^{\mathrm{a}}$ \\
LDL-cholesterol & $0.34^{\mathrm{a}}$ & 0.18 \\
HDL-cholesterol & -0.16 & $-0.34^{\mathrm{a}}$ \\
Plasma cholesterol & $0.49^{\mathrm{a}}$ & 0.22 \\
LOG triglyceride & $0.44^{\mathrm{a}}$ & $0.49^{\mathrm{a}}$ \\
LOG fibrinogen & $0.33^{\mathrm{a}}$ & 0.25 \\
\hline
\end{tabular}

a denotes significant, independent correlations found by multiple linear regression analysis

UalbV $>300 \mathrm{mg} / 24 \mathrm{~h}$ compared with patients with normal UalbV and similar metabolic control $(p<0.05)$ (Table 2). Intermediate values were found in the patients with incipient nephropathy. HDL-cholesterol concentration was not significantly different if the metabolically comparable groups with different UalbV were compared.

In the groups with normal UalbV, the patients with $\mathrm{HbA}_{1 \mathrm{c}}>8.0 \%$ had significantly higher concentrations in plasma of VLDL-cholesterol and lower concentrations of HDL-cholesterol compared with patients with $\mathrm{HbA}_{1 \mathrm{c}}<8.0 \%(p<0.05)$.

Correlation coefficients from stepwise multiple linear regression analysis, including all patients, are shown in Table 3. UalbV correlated independently with the plasma concentration of VLDL-cholesterol, LDL-cholesterol, total cholesterol, triglyceride and fibrinogen $(p<0.01)$. HDL-cholesterol did not correlate with UalbV. $\mathrm{HbA}_{1 \mathrm{c}}$ correlated independently with the plasma level of VLDL-cholesterol, HDL-cholesterol and triglyceride, whilst no correlation was found between blood pressure, serum albumin or serum creatinine and the plasma concentration of lipoproteins or fibrinogen.

\section{Discussion}

The present study comprises patients with insulin-dependent diabetes mellitus with different levels of albuminuria based on three 24-h urine collections. The re- nal function was fairly well preserved in all subjects and their serum creatinine did not exceed $150 \mu \mathrm{mol} / 1$.

The increased level of lipids in plasma in patients with overt clinical diabetic nephropathy compared with patients with normal UalbV, together with the demonstration of raised plasma fibrinogen concentration are in accordance with previous studies [9-12]. However, the demonstration of intermediate plasma concentrations in patients with incipient nephropathy are new and indicate that abnormalities in plasma concentrations of lipoproteins and fibrinogen are an early event in diabetic nephropathy. This is supported by the demonstration of independent correlations between urinary albumin excretion and plasma concentrations of very low and low density lipoproteins and fibrinogen, although renal function was only impaired to a minor degree in the patients with nephropathy. Vannini [12] found no correlation between UalbV and plasma concentrations of lipoproteins in diabetic patients. However, his classification of patients was based on only one 24-h urine sample, which, due to the high day-to-day variation in UalbV, causes a considerable risk of misclassification [19].

The mechanism behind the observed changes in plasma concentrations of lipoproteins and of fibrinogen is still unknown. In patients with non-diabetic nephrosis increased lipoprotein synthesis has been demonstrated as a non-specific response to albumin loss $[20,21]$. The elevated VLDL- and LDL-cholesterol levels in the patients with the most pronounced urinary albumin loss may at least in part be explained by the same mechanism: a non-specific increased plasma protein synthesis in the liver together with a preferential loss in the kidneys of the smaller macromolecules such as albumin (diameter $7.2 \mathrm{~nm}$ ) and HDL (diameter $10 \mathrm{~nm}$ ) compared with the much larger LDL- and VLDL-particles [22]. This explanation may also apply to plasma fibrinogen, which, due to its thread-like molecular structure has an endothelial permeability coefficient comparable to that of LDL [23, 24]. Loss of apoproteins through the kidneys may also interfere with lipoprotein levels in these patients. Plasma concentration of HDL-cholesterol and in part, concentra- 
tions of VLDL-cholesterol and triglyceride, are associated with the long-term metabolic control of the diabetes. Inhibition of plasma lipoprotein lipase increases VLDL-cholesterol and decreases HDL-cholesterol $[25,26]$. It is unknown if glycosylation of this plasma enzyme results in such an inhibition or if a direct interaction between insulin and the enzyme is involved.

Intervention studies in non-diabetic males have associated an $8 \%$ reduction of total plasma cholesterol with a $20 \%$ reduction in cardiovascular mortality and a $10 \%$ reduction of total plasma cholesterol combined with a $12 \%$ increase in HDL cholesterol with a $34 \%$ reduced incidence of coronary heart disease [27, 28]. In the Northwick Park Heart Study among middleaged men a $20 \%$ fibrinogen elevation was associated with an approximately $80 \%$ increased risk of ischaemic heart disease [29]. Although it is reasonable to associate the described risk factors with the increased risk of cardiovascular disease, simple addition of these risk factors can only account for a minor part of the greatly increased cardiovascular mortality in patients with diabetic nephropathy. An additional and probably more decisive factor might be a change in the arterial wall, a change which promotes lipid accumulation and/or facilitates thrombus formation.

Acknowledgments. This study was supported by a grant from the Danish Diabetes Association. The authors thank Ms. Marja Deckert for skilful technical assistance and Dr. C. Binder, Chief physician, for determining the free plasma insulin concentrations.

\section{References}

1. Borch-Johnsen K, Kragh Andersen P, Deckert T (1985) The effect of proteinuria on relative mortality in Type I (insulin-dependent) diabetes mellitus. Diabetologia 28: 590-596

2. Mogensen CE (1984) Microalbuminuria predicts clinical proteinuria and early mortality in maturity-onset diabetes. $\mathrm{N}$ Engl $\mathrm{J}$ Med 6: 356-360

3. Jarrett RJ, Viberti GC, Argyropoulos A, Hill RD, Mahmud U, Murrells TJ (1984) Microalbuminuria predicts mortality in noninsulin-dependent diabetes. Diabetic Med 1: 17-19

4. Borch-Johnsen K, Kreiner S (1987) Proteinuria - a predictor of cardiovascular mortality in insulin-dependent diabetes mellitus. Br Med J 294: 1651-1655

5. Jensen T, Borch-Johnsen K, Kofoed-Enevoldsen A, Deckert T (1987) Coronary disease in young Type 1 (insulin-dependent) diabetic patients with and without diabetic nephropathy. Incidence and risk factors. Diabetologia 30: 144-148

6. Christiansen JS (1978) Cigarette smoking and prevalence of microangiopathy in juvenile onset insulin-dependent diabetes mellitus. Diabetes Care 1: 146-149

7. Parving H-H, Andersen AR, Smidt UM, Oxenbøll B, Edsberg B, Sandahl Christiansen J (1983) Diabetic nephropathy and arterial hypertension. Diabetologia 24: 10-12

8. Feldt-Rasmussen B, Borch-Johnsen K, Mathiesen ER (1985) Hypertension in diabetes as related to nephropathy. Early blood pressure changes. Hypertension 7 [Suppl 2] 1118-1120

9. Valdorf-Hansen F (1967) Coagulability in diabetics. Acta Med Scand [Suppl] 476: 147-157

10. Keiding NR, Mann GV, Root HF, Lawry EY, Marble A (1952) Serum lipoproteins and cholesterol levels in normal subjects and in young patients with diabetes in relation to vascular complications. Diabetes 1 (6): 434-440
11. Eckel RH, McLean E, Albers JJ, Cheung MC, Bierman EL (1981) Plasma lipids and microangiopathy in insulin-dependent diabetes mellitus. Diabetes Care 4: 447-453

12. Vannini P, Clavarella A, Flammini M, Bargossi AM, Forlani G, Borgnino LC, Orsoni G (1984) Lipid abnormalities in insulindependent diabetic patients with albuminuria. Diabetes Care 7: 151- 154

13. Feldt-Rasmussen B, Dinesen B, Deckert M (1985) Enzyme immuno assay - an improved determination of urinary albumin in diabetics with incipient nephropathy. Scand J Clin Lab Invest 45: $539-544$

14. Havel RJ, Eder HA, Bragdon JH (1955) The distribution and chemical composition of ultracentrifugally separated lipoproteins in normal serum. J Clin Invest 34: 1345-1353

15. Jacobsen K (1955) Method for the determination of fibrinogen in plasma. Scand J Clin Lab Invest [Suppl.] 14: 14-16

16. Svendsen PAA, Christiansen JS, Søegaard U, Welinder BA, Nerup J (1980) Rapid change in chromatographically determined haemoglobin $A_{1 c}$ induced by short-term changes in glucose concentration. Diabetologia 19:130-136

17. Larsen K (1972) Creatinine assay by a reaction-kinetic principle. Clin Chem Acta 41: 209-217

18. Hanning I, Home PD, Alberti KGMM (1985) Measurements of free insulin concentrations: the influence of timing of extraction of insulin antibodies. Diabetologia 28: 831-835

19. Mogensen CE, Chachati A, Christensen CK, Close CF, Deckert T, Hommel E, Kastrup J, Lefebre P, Mathiesen ER, Feldt-Rasmussen B, Schmiitz A, Viberti GC (1985-1986) Microalbuminuria: an early marker of renal involvement in diabetes. Uremia Invest 9 (2): 85-95

20. Chan MK, Persaud JW, Ramdial L, Varghese Z, Sweny P, Moorhead JF (1981) Hyperlipidaemia in untreateded nephrotic syndrome, increased production or decreased removal? Clin Chim Acta 117: 317-323

21. Ohta T, Matsuda I (1981) Lipid and apolipoprotein levels in patients with nephrotic syndrome. Clin Chem Acta 117: 133-143

22. Felts JM, Mayerle JA (1974) Urinary loss of plasma high density lipoprotein - a possible cause of hyperlipidaemia of the nephrotic syndrome. Circulation 50 [Suppl. 3]: 263

23. Stender S, Hjelms E (1987) In vivo transfer of cholesterol from plasma into human aortic tissue. Scand J Clin Lab Invest 47 [Suppl. 186]: 21-29

24. Renkin EM (1977) Multiple pathways of capillary permeability. Circ Res 4: 735-743

25. Pietri A, Dunn FL, Raskin P (1980) The effect on improved diabetic control on plasma lipid and lipoprotein levels. A comparison of conventional therapy and continuous subcutaneous insulin infusion. Diabetes 29: 1001-1005

26. Nikkilä EA (1981) High density lipoproteins in diabetes. Diabetes 30 [Suppl. 2]: 82-87

27. Lipid Research Clinics Program (1984) The Lipid Research Clinics Coronary Primary Prevention Trial Results. JAMA 251: $351-374$

28. Frick $M H$, Elo O, Haapa K, Heinonen OP, Heinsalmi P, Helo P, Huttonen JK, Kaitaniemi $P$, Koskinen $P$, Manninen V, Maenpaa H, Malkonen M, Manttari M, Norola S, Pasternack A, Pikkarainen J, Romo M, Sjoblom T, Nikkila EA (1987) Helsinki Heart Study: primary-prevention trial with gemfibrozil in middle-aged men with dyslipidemia. N Engl J Med 317: 1237-1245

29. Meade TW, Mellows S, Brozovic M, Miller GJ, Chakrabarti RR, North WRS, Haines AP, Stirling Y, Imeson JD, Thompson SG (1986) Haemostatic function and ischaemic heart disease. Principal results of the Northwick Park Heart Study. Lancet II: 533-537

Received: 24 August 1987

and in revised form: 14 January 1988

Dr. Tonny Jensen

Steno Memorial Hospital

DK-2820 Gentofte

Denmark 